\title{
The Victim of Historical Child Sexual Abuse in the Irish Courts 1999-2006
}

2017, Vol. 26(5) 562-580

(C) The Author(s) 2017

Reprints and permission:

sagepub.co.uk/journalsPermissions.nav DOI: I0.1I77/09646639|7694706 journals.sagepub.com/home/sls

\author{
Sinéad Ring \\ University of Kent, UK
}

\begin{abstract}
In recent years, Ireland has been rocked by revelations of historical child sexual abuse. This has led to a variety of state responses but one question remains particularly difficult to answer: why did the sexual abuse of children go unrecognized as a societal problem for so long? This article seeks answers by scrutinizing cases in which defendants sought to have their trial prohibited because of the delayed reporting. It explores the legal test used in the period 1999-2006, which focussed on the abuser's 'dominion' over the victim. The use of the notion of dominion elicited valuable information about the reasons for the delay and how children were silenced. Uncovering these stories is essential to understanding the dynamics of child sexual abuse. However, a critical reading of the delay cases that draws on feminist critiques of battered woman's syndrome and rape trauma syndrome reveals law's power to impose hegemonic discourses onto victims and to produce new histories. Under the dominion paradigm, the courts distorted victims' accounts of their experiences and sidelined stories that pointed towards a culture of indifference to abuse. Thus, law is shown to occupy a paradoxical position in relation to Ireland's history of child sexual abuse.
\end{abstract}

\section{Keywords}

Battered woman's syndrome, feminism, historical child sexual abuse, Ireland, law and history, rape trauma syndrome, victims

\section{Corresponding author:}

Sinéad Ring, Kent Law School, Eliot College, University of Kent, Canterbury CT2 7NS, UK.

Email: s.ring@kent.ac.uk 


\section{Introduction}

Like many other countries, Ireland has been rocked by revelations of widespread sexual abuse of children perpetrated decades ago. The heightened public awareness around historical child sexual abuse has led to a variety of responses by the state, including a formal apology by the Taoiseach, the establishment of statutory inquiries, the provision of mechanisms of redress for victims and the institution of criminal prosecutions for historical sexual abuse offences. However, one question remains particularly difficult to answer: why did the sexual abuse of children go unrecognized as a societal problem for so long? Some factors have been identified as important in this regard, such as the state's deferential attitude to the Catholic Church (Department of Justice 2005; Commission of Investigation, 2010; Conway, 2014: 172; Commission to Inquire into Child Abuse (CICA), 2009; Ferriter, 2009a: 442-462), a lack of accountability mechanisms within and between state and non-state bodies (Holohan, 2011: 18), and harmful constructions of childhood, child welfare and sexuality (Buckley, 2013; Powell et al, 2013). It is also clear that some victims of clerical abuse did not report due to a fear of not being believed (CICA, 2009). However, little consideration has been given to the role of Irish society in maintaining the silence that surrounded child sexual abuse for most of the twentieth century. This silence was not necessarily due to an ignorance about the nature and harms of abuse. Rather, it seems that for most of the last century child sexual abuse was well known, if not widely admitted (Ferriter, 2009b: 21; CICA, 2009 Vol III: 114; O’Malley, 2009: 656; Maguire, 2007: 86). Thus, it is important to ask: who was silencing abused children? ${ }^{1}$ Specifically, how were children who were abused in families, residential institutions, day schools, sports teams and other places kept silent? What did adults do when faced with a child who was abused? How did victims - as children, and later as adults - try to resist or cope with a culture of indifference? These questions are important in order for Irish society to begin to understand its role in the dynamics of historical child sexual abuse and to learn how it can better protect children from abuse in the present.

One place to begin look for answers to these important questions is law. From the early to mid-1990s onwards, unprecedented numbers of adults reported to the police (gardaí) that they had been sexually abused as children (Ring, 2013). These cases continue to feature frequently in work of the courts. They involve a much broader range of abuse than that examined by the state inquiries; they include abuse by fathers, uncles, teachers, coaches and school bus drivers, for example. The delay between the abuse and the making of a formal complaint to the police is typically many decades. Defendants charged with historical abuse offences may seek to have their trials prohibited on the grounds that a fair trial is impossible due to the delayed reporting. ${ }^{2}$ The High Court (and, on appeal, the Supreme Court) must decide whether to allow the prospective trial take place. From 1999 to 2006, the courts employed a legal test that involved extensive scrutiny of the reasons for the delay; in particular, whether the victim was suffering under the 'dominion' of the abuser and was therefore unable to report sooner. If dominion was found to have existed, the delay was held to be justified and the trial was usually allowed to proceed. This test was replaced in 2006 with one that focusses on the unfairness of the prospective trial. 
This article focusses on the written decisions issued by the High Court and Supreme Court from 1999 to 2006 in relation to applications by defendants to have their trials prohibited. The jurisprudence developed in this period under the dominion test is a rich resource for anyone interested in understanding the history of child sexual abuse in twentieth-century Ireland. The volume of cases decided is of note: using the databases Westlaw, Justis and the official courts website www.courts.ie, I found 54 written judgements from this period. For a small jurisdiction, this is a very high figure and indicates the importance of the delay issue in Irish criminal justice. Importantly, during this period the courts produced lengthy written judgements dealing with the circumstances surrounding the allegations and the fairness of the prospective trial (Ring, 2009). The judgements rehearsed in detail victims' testimonies of their experiences and the reports of psychologists who examined them. This level of detail and reliance on affidavits is a unique resource for researchers; trial judges do not issue written judgements and transcripts are rarely seen by anyone other than the parties, if at all. Most routine trials of historical child sexual abuse are not reported and only a few reach the appellate courts.

The dominion case law also provides valuable insights into how law (re)constructs the past. This article will show that law has produced authoritative stories that do not necessarily accord with the full complexity of the accounts offered by victims. The critical reading of the cases offered here shows that law (using the frame of psychology) produced a simple narrative of the passive and traumatized victim paralysed by the domination of the abuser. Not only did this perpetuate stereotypes about 'real' rape victims, it closed off broader questions about the structural factors and power relations that facilitate sexual violence. Furthermore, victims who did not fit the dominion narrative - such as those who attempted to report at the time, or those who went on to lead happy and healthy lives - were forgotten by law. Thus, the delay jurisprudence is a powerful reminder of law's power to impose identities. This is particularly worrying in the context of child sexual abuse, because placing limits on the boundaries of victims' experiences may make it more difficult for current and future abused children to have their experiences recognized and acted upon by adults and by the law. Indeed, the delay cases show that law's power goes even further; it creates new histories. Evidence of societal complicity or acquiescence in the silencing of abused children who did try and report was erased so that law's truth became the simple idea that abuse could not be reported until the end of the twentieth century. In this way, questions of how children were silenced by adults, and how the culture kept them silent for decades after the abuse, have become irrelevant to law. Asking these kinds of questions is a particularly important exercise given the Irish State's reluctance to engage with the past. There exists no national memorial to victims of institutional child abuse (despite the recommendation to this effect in CICA, 2009: 27); victims who received payments from the Residential Institutions Redress Board (RIRB) are subject to the threat of criminalization and imprisonment if they speak about their settlement, ${ }^{3}$ and plans are underway to seal the records of people who engaged with the RIRB for 75 years without any provision for access for researchers. ${ }^{4}$ In this context of state minimization, scholars are presented with a challenge to continue to ask questions about why victims remained silent and to discover whether further silences around child sexual abuse might be being created in the present. 


\section{Structure}

The first section sets out the genesis of the jurisprudence in relation to defendants' applications to prohibit their trial on historical abuse charges. Particular emphasis is placed on the development of the notion of 'dominion'. The second section examines the harms of dominion and highlights the similarities between dominion on the one hand and battered woman syndrome (BWS) and rape trauma syndrome (RTS) on the other. Both syndromes are legal constructs employed to make audible to law the experiences of victims of domestic and sexual violence. Feminist critiques of these syndromes are employed to unpack the problematic construction of victims' experiences within the trope of dominion. The third section provides a close reading of a sample of the delay cases between 1999 and 2006. In the cases selected, victims disclosed the abuse to an adult at the time, but their disclosures were not acted upon. Particular attention is paid to the evidence of victims' resilience and agency and how the courts interpreted the notion of dominion in a way that silenced these elements of victims' histories and closed off consideration of the indifference shown by adults at the time. The final section reflects on what the delay cases from 1999 to 2006 reveal about law's capacity to create new subjectivities and histories and considers the implications for Irish society's understanding of its past. Throughout this article, the term 'victim' is used, rather than 'survivor' or 'complainant', in order to give expression to the position of the person who suffered the abuse and called on law to act.

\section{The Evolution of the Delay Jurisprudence}

Although statutes of limitations do not apply to serious crimes in Ireland, the established view prior to the advent of large numbers of historical abuse prosecutions was that delay by the prosecutor or by the victim was fatal to a prosecution. This was founded in a commitment to defendants' rights. The approach proved particularly harsh in child abuse cases; in 1992, a delay of one year rendered a child's complaint of abuse inadmissible (People (DPP) v Synott (29 May 1992, unreported, Court of Criminal Appeal)). However, in response to the changed context of the early to mid-1990s, the High Court and Supreme Court adopted a more flexible approach to delayed reporting of child sexual abuse (Ring, 2013).

The case of $B v D P P$ [1997] 3 IR 140 heralded the new approach. The defendant was charged with 69 counts of indecent assault and rape offences against three of his daughters between the years 1962 and 1974. The Supreme Court held that the defendant's right to a trial with reasonable expedition was to be balanced against the right of the community to have offences prosecuted. The key issue in achieving this balance was whether the delay was 'reasonable'. In answering this question, the Court had to determine whether the defendant had exercised 'dominion' over the victims. Dominion was essentially a legal version of a psychological explanation for delayed reporting, based on the traumatic effects of sexual abuse. The Court quoted directly from the psychologist's affidavit: '[a]s a direct result of this psychological reaction to the abuse [the victim] was unable to report the matter to an external 
agency, and did not discuss it with her own mother until she was aged approximately 25 years' (1997:197).

This dominion-centred approach was confirmed by the Supreme Court in $P C v D P P$ [1999] 2 IR 25 (hereafter $P C$ ). $P C$ was the leading judgement in this area until it was replaced in 2006 in the case of $S H v D P P$ [2006] 3 IR 575 (hereafter $S H$ ). It required the Court to ask (1) whether, depending on the nature of the charges, the delay was such that, despite the absence of actual prejudice, the trial should be prohibited; (2) what were the reasons for the delay and whether, assuming the complaint to be true, the delay in making it was referable to the accused's conduct; (3) whether the accused had suffered actual prejudice such that the trial should not be allowed to proceed. The inquiry focussed on (2), which required an assessment of whether the defendant's dominion over the victim had prevented timely reporting. Denham J quoted extensively from the psychologist's affidavit, which set out the reasons why a victim might not report for many years, if ever. It explained that the dynamics of child abuse often involve a known adult in a legitimate position over a child who exploits the accepted patterns of dominance and authority to engage the child in sexual activity. It also stated that there may be many reasons why the victim may not complain for a long time: feelings of guilt; the abuser may be a person in authority held in high esteem not only by the victim but also by adults and the child's parents. In such circumstances, the victim may feel that $\mathrm{s} /$ he will not be believed if $\mathrm{s} / \mathrm{he}$ complains. Alternatively, s/he may be daunted by what s/he sees as the difficulty in having the story accepted. The affidavit went on to explain that when the victim matures and is no longer under the influence of the abuser and is in a better position to understand how $\mathrm{s} /$ he has been wronged, s/he may still feel prevented from making a complaint because the recall of the incidents might be humiliating. In addition, the victim may feel that publication of the fact $\mathrm{s} /$ he has been abused would be humiliating. Victims might not be able to talk about the abuse because of an unhealthy attitude to sexuality or they may not be able to view the abuse as a criminal offence or they may have decided to put it behind them. The affidavit went on to state that many adult victims decide to make a formal report after undergoing the process of counselling, in which they realize the seriousness of the abuse they suffered (1999: 59-60).

From the decision of $P C$ in 1999 until it was replaced in 2006, dominion was the key issue for courts hearing applications brought by defendants to halt their trial on historical child sexual abuse offences. If dominion was found, the delay was held to be reasonable and thus excusable. Therefore, a finding of dominion usually meant the trial would go ahead; conversely, if no dominion was found (which was rare), the defendant was more likely to succeed in having the proceedings stopped (Ring, 2013). In order to decide the dominion issue, the High Court would examine the victim's affidavit, which contained detailed accounts of the abuse, as well as explorations of the reasons for the delay. The Court also received the reports of assessments by clinical psychologists of the victim(s), in which they would give an opinion as to whether the delay could be attributed to the abuse. Psychologists were required to go beyond a mere rehearsal of the literature and to offer an opinion on the individual being assessed. They were cross-examined at length on their reports (O’Malley, 2009: 661). In their written judgements, the High Court and Supreme Court would explore the dominion issue at length, citing the victim's affidavit, as well as the psychologist's affidavit and testimony. The judgements contained lengthy 
and detailed consideration of the reasons offered by victim for the delay and a detailed consideration of the psychologist's assessment of whether the delay was 'reasonable'. Thus, the courts developed a considerable body of cases between 1999 and 2006 that focussed primarily on dominion.

The development of the dominion discourse can be understood as a progressive moment in Irish law's treatment of victims of historical child sexual abuse. Dominion allowed law to carve out an exception to the established approach to delay in criminal prosecutions and allowed the prosecution of sexual offences committed against children decades earlier. The reasons for the victim's silence were taken seriously as a justification for changing the established rules of criminal procedure. This indicates the flexibility of the common law and the willingness of the courts to recognize the victim of childhood sexual violence as a legal subject whose rights to bodily integrity, to autonomy and to privacy require vindication.

Furthermore, the admission of and reliance by the High Court and Supreme Court on psychologists' reports and testimony was an important move by law to bring expertise about the effects of sexual abuse into its process. Feminist scholars have long argued for courts to receive similar expertise in rape and sexual assault trials (Ellison, 2005; Smart, 2000).

However, there are other readings of the courts' use of dominion that expose its problematic construction of victims' subjectivities and its effects in shutting down important questions about Ireland's history of child abuse. The next section explores these readings.

\section{Dominion's Harms}

A close reading of the cases decided under $P C$ reveals a number of problematic constructions of victims of historical child sexual abuse. Many of these have strong resonances with the construction of women under the BWS defence and RTS. Therefore, despite the radical appearance of dominion, on closer examination, it has continuities with a controversial tradition in law of using psychological discourses to articulate the experiences of victims of domestic and sexual violence. Before considering how dominion constructed victims in problematic ways, the next subsection sketches the contours of BWS and RTS and sets out the feminist critiques of both.

\section{(i) BWS}

BWS is a psychological category that describes the psychological consequences and patterns of behaviour that result from cyclical violence and long-term abuse (Walker, 1984). BWS is included in the American Psychiatric Association's (2013) Diagnostic and Statistical Manual of Disorders (DSM) as a sub-category of Post-Traumatic Stress Disorder (PTSD). According to Walker, a battered woman may experience a state of 'psychological paralysis', which can only be ended by an act of violence on her part. The theory has had a significant impact on the treatment and prosecution of cases where a battered woman is charged with the killing of her violent partner. It was 
influential in Canada and to a lesser extent in England and Wales throughout the 1990s ( $R v$ Lavallee [1990] $1 \mathrm{SCR} 852$; Wells: 1994), but it is not as popular now. It has been subjected to sustained critique by feminist scholars (Raitt and Zeedyck, 2000, Chapter 4). One major criticism is that BWS ignores the fact that domestic violence is not an exceptional form of violence but is a structural phenomenon that might affect any woman (Mahoney, 1994). As such, psychological evidence to explain the context of an abusive relationship is only needed because of law's refusal to accept the reality that violence is a feature of many women's lives. Furthermore, scholars note that there is nothing unusual about women's decisions to stay, to abandon the attempt to leave, or to return. Given the lack of other viable choices for women who wish to leave and the risk of further violence or death associated with leaving, staying in an abusive relationship may well be the only rational choice available, and not a kind of 'learned helplessness', as suggested by BWS. However, law refuses to accept this and demands expert psychological evidence that a woman suffered BWS. In this way, her 'unreasonable' behaviour in staying in an abusive relationship becomes understandable to law, but in the process women are characterized as passive, dependent and disordered (Sheehy et al, 1992).

\section{(ii) RTS}

Expert psychological evidence has also had an important role to play in legitimating the experience of rape victims. The law has traditionally treated the evidence of victims of sexual offences with extreme scepticism (Hanly et al, 2009; Temkin and Krahé, 2008). Numerous reforms have been aimed at making the trial process a more positive experience for rape victims, such as the introduction of limits on questions about previous sexual experience, ${ }^{5}$ the removal of the mandatory corroboration warning ${ }^{6}$ and allowing special measures to be used to facilitate victims giving evidence. ${ }^{7}$ Despite these improvements, however, myths about the behaviour of 'real' rape victims persist (Ellison and Munro, 2009a; Temkin et al: 2016). RTS comprises a constellation of reactions and behaviours of women who have been raped (Burgess and Holmstrom, 1974). Like BWS, it has also been included in the DSM as a sub-category of PTSD. Expert evidence on RTS has been used by the prosecution to explain some victims' apparently 'counter-intuitive' behaviours, such as failure to immediately report a rape, lying to the police, refusing to name the perpetrator, exhibiting emotional 'flatness' and returning to the scene of the attack. In the United States in particular, RTS proved helpful in educating jurors about 'real rape' stereotypes.

However, feminist scholars have exposed the problems with RTS. It reinforces the belief that women's reactions to rape are pathological (Stefan, 1994) and constructs all rape victims as traumatized, despite their individual characteristics (Gilfus, 1999). It also imposes a standard that all victims have to meet in order to be believed (Raitt and Zeedyk, 2000: 100). RTS has also been criticized for providing support to improper attacks on the victim's credibility by the defence. Furthermore, because RTS is based on psychological constructs and is linked to ideas such as denial, this is said to expose rape victims to a form of symbolic violence, in which one legitimate 
interpretation is that others know better than the victim herself, or the victim is no longer in control of meaning making of her life and sense of self (Gavey and Schmidt, 2011). Perhaps most importantly, a focus on the pathology of individual victims diverts attention from the wider structural context of pervasive male violence against women. Therefore, expert evidence on RTS (unlike general educational guidance to jurors on the effects of rape: Ellison and Munro, 2009b) only bolsters law's individualized approach to the problem of rape and allows law to ignore the societal context in which it takes place.

(iii) How the insights gained from feminist critiques of BWS and RTS may be applied to dominion in historical child sexual abuse cases

The feminist critiques of BWS and RTS provide valuable insights into the roots of dominion and its problematic effects on the courts' construction of victims' subjectivities. Of course, the $P C$ test's concern with checking the delay was 'justified' was an expression of the criminal courts' anxiety about all delayed prosecutions and was an attempt perhaps to identify a public interest in allowing these exceptional cases to proceed. However, on closer examination, it is clear that due process was not at the heart of the test. After all, in looking for dominion, the court was required to suspend the presumption of innocence and assume the truth of the complaint (1999: 68). Furthermore, the question of fairness of trial in evidential terms is logically unconnected to that of whether any delay in reporting the alleged crime was justified. Rather than flowing from the criminal law's concern for defendants' rights in delayed prosecutions, then, the inquiry into the reasons for the delay can better be understood as being primarily based on law's historical distrust of sexual violence and domestic violence victims. In $P C$, the Supreme Court chose to make the reasons for the delay relevant on the ground that the delayed reporting was prima facie unreasonable and blameworthy. This resonated with the myth that 'real' rape victims complain at the earliest opportunity. Furthermore, the requirement to check if the psychologist had deemed the reasons for the delay to be 'reasonable' fits squarely within requirements of independent validation or corroboration of the testimony of sexual assault victims. When considered in this light, dominion becomes, like BWS and RTS, indicative of law's inability to move beyond unfounded assumptions about victims of sexual violence.

Second, dominion interpellated the victim into a universal identity of the traumatized and passive victim. This meant that anyone who was not psychologically damaged 'enough' would be excluded from the category of dominion. In one incest case, the victim's fear of causing problems in her family was not sufficient to excuse the delay in reporting ( $P C v$ Malone [2002] 2 IR 560). ${ }^{8}$ In $J L v D P P$ [2000] 3 IR 122, the fact that the abuse was not part of a systematic pattern of abuse meant that the delay was inexcusable, despite the psychologist's finding that the delay was reasonable. Furthermore, victims were required to have conformed to a traumatized identity throughout their adult lives. Indications of psychological health and coping mechanisms in adulthood were found to be inconsistent with dominion. In TS v DPP [2005] 2 IR 595, a case involving complaints dating back to 1958, the Supreme Court quoted extensively from the psychologist's 
report, which stated that the delay was reasonable. However, because the psychologist had conceded under cross-examination that neither victim had any serious psychological or psychiatric problems, it was 'hard [for the Court] to place too much reliance on [the psychologist's] evidence' (2005: 605). Dominion was not found in a case where the victim went on to enjoy a supportive relationship as an adult ( $P C v D P P$ [2005] IEHC 103). Nor was it found where the victim decided to remain silent as an adult because of a concern for her career in the gardaí ( $D P P \vee J O^{\prime} C$ unreported High Court, 27 July 2001). Thus, like BWS and RTS, dominion operated to disqualify certain victims of historical child sexual abuse who did not fit the individualized and disordered identities required by dominion.

Third, dominion closed off consideration of the broader societal factors why a child remained silent for so many years. This was despite the promise of dominion as a frame for law to understand the victim's experience. Indeed, dominion, like BWS and RTS, was a way of giving context and detail to the abstract legal subject in these difficult cases. This allowed law to push beyond the narrow confines of the abstract legal subject and come closer to the lived reality of victims' experiences. However, just as with BWS and RTS, dominion failed to offer law a way of seeing the broader societal and structural factors surrounding sexual violence against children (Chunn, 2002; Kitzinger, 1997; Keenan, 2012) and the social context in which a child could be prevented from reporting. Instead, the courts preferred to attach all responsibility for the delay to the actions of the defendant in (allegedly) abusing the victim. Thus, the defendant's actions were the cause of the victim's passive and traumatized identity. Just as BWS and RTS translates the deeply structural and political issue of violence against women into a private mental health crisis, dominion expressed the fiction that the delay was an individual's disordered reaction to the crime. In this narrative important historical questions inevitably got lost, such as were there other reasons, beyond the effects of the abuse, why victims remained silent in the decades after the abuse? Why was the criminal law so ineffective in protecting children? What was the role of parents, teachers and other members of society in sustaining a culture of silence around sexual violence against children?

Therefore, law, using the notion of dominion, perpetuated older stereotypes about the credibility of victims of sexual violence, created new subjectivities of victims that did not correlate with their lived experiences and closed off questions about the broader societal context in which abuse took place. However, perhaps the most worrying dimension of dominion was how the courts dealt with victims whose very existence called into question the notion of dominion. These were people who gave evidence on affidavit that they had not remained silent until recently but had in fact attempted to disclose the abuse as children and were not listened to. These stories provide insights into the silencing of children by adults who were not the abuser. How law treated these stories of agency and resilience under the dominion paradigm reveals law's power to create new histories.

\section{Stories of Agency and Resilience}

This part scrutinizes a small selection of the delay cases. They were chosen because they contain evidence presented by the prosecution to the effect that the victim did disclose 
the abuse at or around the time of the abuse, but the adult to whom they disclosed did nothing. The evidence presented by victims in these cases suggests a culture that was indifferent to the harms of child sexual abuse. Furthermore, law, using the trope of dominion, subordinated themes of agency and resilience in these victims' accounts and refused to consider their treatment by adults to whom they disclosed. In examining these cases, there is no suggestion that there is a 'correct' way to represent victimhood in historical sexual abuse cases, nor is there any desire to contribute to an unhelpful binary construction of victims as either agentic or not. Most importantly, there is no suggestion that people who did not report at the time are less important or less deserving of justice. Rather, the intention is to show that stories of victims' agency and stories of inaction by adults were present in the case law and that the law closed off consideration of these elements of the stories.

In the seminal case of $P C$, the charges were five counts of indecent assault and three counts of unlawful carnal knowledge, dating back to the early 1980s. The defendant was a bus driver who drove school children to swimming lessons. The abuse of the victim, who was aged between 12 and 15 years at the time, was alleged to have taken place on the bus, in the swimming pool and elsewhere. The victim did not disclose the abuse until 1988, when she was in her final year of school. She told her classmates, her parents, a teacher and the head teacher. Her motivation for telling the head teacher was to protect other potential victims, which indicates her altruism and resilience. She also told a garda sergeant who was a friend of her parents. Unfortunately, instead of pursuing the matter, he told the victim to inform her parents if she had any problems with the defendant. The victim went on to complete her university education and put the abuse out of her head until she finally made a formal complaint to the gardaí in 1995.

In the Supreme Court, Denham J, Keane CJ and Lynch J gave written judgements. Denham $J$ held that because of his status as an adult and his position of authority, the defendant had been in a dominant position over the victim while she was in school. The victim's decision not to make a formal complaint in 1988 was 'entirely comprehensible in light of the reaction she got to her initial disclosure of the abuse. She was not supported. She was not brought to a counsellor. She was not brought to a garda station (1999: 63). Thus, the fact that the authority figures in her life did not take appropriate action in 1988 was part of the circumstances. However, Denham J quickly moved on from this insight to say that the delay was in fact caused by the defendant:

The delay was caused by the [victim's] inability to make a formal complaint until 1995 . This was a consequence of the alleged sexual abuse, the alleged criminal actions. Thus, fault lies with the alleged perpetrator of the actions - the [defendant]. (1999: 63)

Denham J did give a nod to broader factors involved in the silencing of children when she stated: 'It appears that rational consideration of abusive events is frequently suppressed for complex personal, family and social reasons' (1999: 64). She then went on to inquire as to whether the defendant would risk an unfair trial and held that he would not. Keane CJ also relied on the psychologist's evidence to say that the delay was explicable in light of all the circumstances, including the lack of action by adults in 1988. However, the delay was ultimately the result of the defendant's actions. Both of these judgements 
show that the Court placed most emphasis on the negative psychological effects of the abuse on the victim and thus underemphasized her agency in reporting in her final year of school to protect other children. Furthermore, the failures of a number of adults to take the problem seriously became merely a minor detail in the story told by the Court. This theme of minimization of stories of victims' agency and inaction by responsible adults is also clear in other cases decided under the $P C$ test.

In $S F v D P P$ [1999] 3 IR 235, the accused was a Roman Catholic curate charged with 66 counts of indecent assault or gross indecency against eight boys aged 11 or 12 years of age in the period 1981-1987. The victims were altar boys. The appeal to the Supreme Court concerned the charges relating to one victim who had reported the abuse to the defendant's replacement following his departure from the parish in 1986. He also spoke about the abuse to a person in All Hallows College, an educational institution for priests and nuns. He was asked to write down everything that had happened to him and subsequently received a letter of thanks from the local bishop. The letter did not specifically refer to the allegations. Nothing else was done to address the allegations. He eventually reported to the gardaí in 1995. The Supreme Court found that the continued delay in reporting the complaints to the gardaí was to be attributed to the continuing psychological damage and/or 'sequelae' of the abuse (1999: 252). The Court then found that that there was no specific prejudice caused by the delay and the application for prohibition was denied. Clearly then, the logic of dominion could not accommodate the part of the story that showed the victim's courage and rationality in attempting to bring the abuse to the attention of the Church authorities. Instead, the Court imposed the dominion narrative. Not only did this deny the reality of the experience conveyed to the Court, but it also translated the failure of the Church authorities to stop the abuse into a minor detail in the Court's account of the past.

$P J C v D P P$ [2005] IEHC 98 and $R C v D P P$ [2005] IEHC 97 were two of a cluster of cases involving a long and complicated history of abuse in a family. ${ }^{9}$ PJC was charged with 21 charges of indecent assault on his niece between the years 1978 and 1983. She was aged between 10 and 15 years at the time. She gave evidence that when she was about 15 she told her doctor about the abuse. The doctor suggested that she should attend the Rape Crisis Centre. It seems that no further action was taken to protect her or the other children. In 1987, the victim made a statement to the gardai where she described abuse by her uncles but not the defendant. This statement was withdrawn. She eventually made a formal complaint in 1999. MacMenamin $\mathrm{J}$ found that the delay and the withdrawal of complaints were due to dominion and oppressive conduct by the defendant and other members of his family. The fact that a doctor and the gardaí had been alerted to the sexual abuse within the family did not feature in the Court's reasoning.

In $R C$, the defendant was charged with nine counts of indecent assault against his two nieces. In relation to one victim, the charges dated back 21-23 years to when the victim was aged between 15 and 18 years. The psychologist's evidence was that when she was 17 or 18 , she tried to formally report the abuse, but the garda she met told her to leave the station and made derogatory remarks about her family. When she tried to tell her father about the abuse, he ordered her to keep quiet. As a result, she chopped all of her hair and slashed her face with her father's razor. She eventually reported the abuse in 1999. MacMenamin J also recited and accepted the evidence of a social worker that allegations 
of abuse within the family in question had been brought to the attention of the Eastern Heath Board. Meetings were held with the family, but ultimately the accused avoided any further interaction with the social services by emigrating to England with his family in 1988.

The Court refused to grant the order of prohibition on a number of grounds, including the familial relationship, the close proximity of the victim's and defendant's homes, the victim's fear of the defendant and his brother and the 'dominion conduct on the part of the [defendant]'. In so doing, the Court sidestepped any consideration of the agency and courage shown by this young woman in looking for help from responsible adults. This simplistic approach transformed the original story of a complex array of factors relating to the victim's silence over 21 years into a simple story of a damaged victim who was afraid of the defendant and his brothers. Thus, in both $P J C$ and $R C$, the focus on the dominion issue meant that law effectively exonerated both the gardaí and the social services.

$J O^{\prime} C v D P P$ [2000] 3 IR 478 involved systematic abuse of the victim when she was aged between 10 and 14/15 years old, in the years 1974-1978. The victim lived next door to the defendant. The victim's parents were very friendly with the defendant who was a garda. In this case, the Supreme Court took the opportunity to explore the ways in which the delay jurisprudence was developing. The lead judgement was delivered by Keane CJ who quoted the victim's statement in its entirety. He also quoted extensively from the affidavits of the expert consultant psychologist who had examined the victim. The victim told her mother about the abuse in 1988 when she was a young adult. However, her parents did not take any action at that time. She finally made a complaint almost 10 years later to the Eastern Health Board, having realized through counselling that she was not to blame for the abuse. She also was motivated by a desire to protect a child who was living next door to the defendant. Keane CJ relied on the psychologist's evidence to the effect that the delay was explicable on the ground that her parents had not acted on her disclosure of abuse in 1988 (2000: 485). This was an important judicial recognition of the role of people other than the defendant in keeping victims silent. However, Keane CJ did not pursue this point but simply stated that the delay was 'ultimately referable to the defendant's actions, assuming them to be true'. The order of prohibition was refused. Therefore, dominion was used to convert what was completely understandable behaviour on the part of the victim into a matter that needed to be certified by a psychologist and that was ultimately an effect of the abuse. In this way, the Court elided any consideration of how the defendant's status as a garda could have provided him with a certain degree of immunity, and it also shut down the discussion of her parents' failure to act in 1988.

SA v DPP [2005] IEHC 262 involved eight charges of buggery, three charges of indecent assault and one charge of attempted buggery by a Christian Brother against six children, five of whom were residents or inmates of an industrial school and one of whom was a grandchild of an employee of the Christian Brothers. The offences against the inmates were alleged to have been committed between 1961 and 1964, and the offence against the sixth victim was alleged to have been committed between 1964 and 1969. One victim stated that he complained to the school authorities and the 
defendant was removed from his position. However, he received a three-day long beating from other members of the religious congregation. When he left the school, he did not report because of a fear of not being believed, a fear that was confirmed when he spoke with a psychiatrist in 1969. Another victim did not complain because of his feelings of shame and because of the status of the Christian Brothers in Irish society. Another victim did not report because of a fear of getting a physical beating and a fear that no one could believe him since the defendant was 'a man of the cloth'. This fear was echoed in the evidence of another victim, who did not think anybody would believe that a member of the Catholic Church would be involved in that kind of activity. For four of the six victims, the psychologist's evidence involved assessing their behaviour according to the Trauma Symptom Inventory.

In deciding not to prohibit the trial, O'Neill $\mathrm{J}$ held that the psychologist's evidence reinforced and added to the reasons given by the victims for the delay. This case also points up the deeply embedded social disbelief of victims of clerical abuse. This was not, contrary to the logic of dominion, something that clerical abusers were responsible for (although they surely exploited their status in order to offend: Keenan, 2012) but was rather a result of the prevailing deferential attitude in society towards the Catholic Church. The fact that children felt that they could not report because of a climate of disbelief is a very important consideration for any society attempting to come to terms with its past. However, the Court in $S A$ was far more interested in gaining expert certification of victims' stories and in making each victim's story part of an individualized narrative that expressed their inability to complain, rather than in exploring society's role in preventing disclosure.

\section{The Delay Cases and Ireland's Relationship to Its Past}

The courts' focus on dominion was rooted in the well-intentioned aim not to allow the defendant to escape prosecution merely because of the passage of time. However, close examination of the cases reveals that the dominion discourse also had a number of other consequences. It silenced stories of agency and resilience of victims who tried to report at the time or at an earlier point in their lives, in order to maintain the fiction of the traumatized victim. Dominion was therefore part of a continuum of silencing in law and in society, which involves processes that distort, minimize and discount the testimonies of victims of sexual violence (Haaken, 1998; Young, 1998).

The dominion discourse also excluded any consideration of the role of society in keeping victims silent. This is especially significant because the cases presented in the previous section suggest that a key factor in non-reporting in those cases was that family members, or other adults in positions of responsibility over the child, failed to act when told by the child about the abuse. The stories examined point to an attitude of indifference on the part of some gardaí, religious, teachers and social workers towards the problem of child sexual abuse. Children were silenced in a variety of ways, including a failure to provide support $(P C)$, minimization and mocking $(P J C)$, a refusal to act $(S F)$, societal attitudes towards the Catholic Church $(S A)$ and the abuser's societal status $\left(J O^{\prime} C ; S A\right)$. They also suggest that the reason other children did not report was that they were living in a society in which there was no reason to expect action on sexual violence 
by adults. However, law subordinated all of these stories into a narrative that attributed full responsibility for the delay to the alleged abuser and thus produced a decontextualized version of history.

Of course, this approach might be seen as mandated by the individualized logic of criminal law, which does not hold a society to account for failures to protect victims. However, this does not mean that the courts were compelled to take the approach they did. The 'delay' could have been constructed within legal doctrine not as presumptively blameworthy, but as a rational response to a repressive culture, in which Irish society was complicit. This approach would not have had any bearing on the ultimate question for the court, which was the likelihood of the defendant receiving a fair trial. Neither would it have risked prejudicing the jury because these were pre-trial judicial review applications.

Instead, law produced 'frames of remembrance' (Irwin-Zarecka, 1994) that set parameters on how Irish society understands its past. This process reached its conclusion in the case of $S H$ when the Supreme Court replaced the $P C$ test with one that asks only whether the defendant runs the risk of an unfair trial (Ring 2009, 2013). It is difficult to ascertain exactly why the Court decided to institute a new test. However, it would seem that it was responding to uncertainty among judges and practitioners about the principles governing the so-called sex delay cases (Conroy, 2005; Carolan, 2006) as well as a growing trend of defendants seeking to have the victim examined by their psychological experts, which involved further delays (Carolan, 2006). There had also been indications of a move towards the eventual $\mathrm{SH}$ approach in the earlier judgements of Hardiman and Murray $\mathrm{JJ}^{10}{ }^{10}$ While the decision is an undeniably positive one from a due process perspective (Ring 2013), it has entrenched law's refusal to engage with structural and societal issues surrounding child sexual abuse.

The accused in $S H$ was a primary school teacher facing 50 charges of indecent assault against four victims, who were all aged between seven and ten years at the time. The offences were alleged to have been committed in the mid to late 1960s but no formal complaint was made until 1999. The appeal from the High Court's refusal of an order of prohibition was heard before five judges of the Supreme Court. The Court received full legal submissions about the jurisprudence relating to the right to a fair trial and the need to inquire into the reasons for the delay. In the case report in the Irish Reports, the transcript of the lawyers' oral arguments is reproduced, including questions from the bench. This indicates the importance of the case in setting a new precedent in historical child sexual abuse cases.

Murray CJ gave the judgement of the Court. He set out the evidence given by the four victims regarding the abuse and their reasons for not reporting contemporaneously. The evidence of one victim, JM, resonated strongly with the theme of disbelief running through the cases. JM told his mother about one particular incident of abuse. She eventually believed him and brought him to a garda station to report. His mother told a uniformed garda about the assault - all JM could remember from this episode was shouting between the Garda and his mother (2006: 603). On returning home, the victim's father beat him for having made the allegation. The complaint was not pursued any further. The other victims cited similar reasons such as disbelief by others and fear. Murray CJ also referred to the report prepared for the Court by Dr Harry Ferguson, an 
academic and professional social worker who had researched the files of the Irish Society for the Prevention of Cruelty to Children. His evidence was that,

Any 'disclosure' of sexual abuse that occurred in decades prior to the late 1980s and 1990s cannot reasonably be defined or treated as a disclosure in the sense that that term is understood today, given the massive social pressure that existed which rendered the child's statement illegitimate and a protective response unthinkable. (2006: 617)

Murray CJ did not comment on this part of Dr Ferguson's evidence but simply stated that it correlated with the experience of the Court and that

the court's experience extends to a broader set of issues and it has found that there is a range of circumstances extending beyond dominion or psychological consequences flowing directly from the abuse which militate or inhibit victims from bringing complaints of sexual abuse to the notice of other persons, in particular those outside their family and even more particularly the gardaí with a view to a possible trial. (2006: 618)

This was a long overdue acceptance by the Supreme Court that a climate of disbelief existed for decades in Ireland. Murray CJ stated that at issue in each historical abuse prosecution is the constitutional right to a fair trial and that 'in reality the core inquiry is not so much the reason for a delay in making a complaint by a complainant but rather whether the accused will receive a fair trial [... ]' (2006: 618). He noted 'the extensive affidavits and oral evidence along with psychological and medical reports which have come before the court for the purpose of explaining the [delay]' and held that 'in the end, what concerns the court is whether an accused will receive a fair trial or whether there is a real or serious risk of an unfair trial' (2006: 618). On this basis, the Court decided that it was no longer necessary to inquire into the reasons for the delay. The only inquiry now is whether the defendant is at risk of an unfair trial because of the delay and whether there are wholly exceptional circumstances which justify an order of prohibition (Ring, 2013).

The $S H$ test is a welcome vindication of the importance of the presumption of innocence and the right to a fair trial. However, it also points up law's power to make parts of victims' histories relevant or not to its treatment of the past. Despite effectively taking judicial notice of a culture of indifference towards abused children, the Court refrained from any detailed discussion of how society kept children silent. In doing so, it missed an opportunity to formally acknowledge the role played by society in the dynamics of child abuse. This omission is particularly regrettable because under $S H$, courts hearing prohibition applications no longer receive evidence on the particular ways in which victims were silenced by adults. Of course, these stories may still be told in courtrooms during trials when victims are asked about the circumstances of the abuse and how they eventually came to report. However, these stories are not being told to the Superior Courts and are not repeated by them in their written judgements. Therefore, Irish society has lost a rich repository of information on its history of child sexual abuse.

The dominion case law is a powerful reminder of law's power to impose hegemonic discourses on victims of sexual violence. This power endures even post- $\mathrm{SH}$; for example, at trial, defence lawyers may argue that certain grounds for delayed reporting are 
'unreasonable' and indicative of dubious credibility. This matters for child victims today too, because the stories adults are allowed to tell about child abuse limit the stories children can tell about it (Woodiwiss, 2014). Therefore, if adult victims have been made to conform to a discourse of trauma and passivity, it is very possible that law will similarly construct boundaries around the permissible limits of the stories that children can tell about their experiences. It is imperative that spaces are created within law and society where adult victims of historical abuse and child victims can express the full complexity of their experiences.

\section{Conclusion}

As societies grapple with the problems of ensuring that child sexual abuse is adequately addressed in the present and into the future, a key objective must be finding out why sexual abuse was invisible in so many countries for so long. The cases presented here offer some insights into the answer in relation to the Irish context. They suggest that a significant factor in some cases of delayed reporting was a failure by adults to act when the child told them about the abuse. They also suggest that it is not legally or historically correct to attach all blame to individual abusers or institutions. The experiences of victims presented to the courts in the period 1999-2006 indicate that parents, teachers, gardaí and other members of society were involved in creating and sustaining a culture of silencing around child sexual abuse that existed not only during the period of abuse but for decades afterwards. If Irish society is serious about reducing the incidence of child sexual abuse, the burden is on the community to create a climate of safety and transparency, in which the abuse of children is not tolerated and in which children are supported in reporting.

Furthermore, the delay cases suggest that law cannot be trusted to produce a complete picture of the past. Rather, they point to law's discursive power to produce new subjectivities at odds with victims' accounts, to perpetuate stereotypes about victims of sexual violence and to produce versions of history that erase certain experiences and exonerate society from any complicity in the abuse of children. If we are to work towards developing a common ethical memory of the past that is the converse of political amnesia (Pine, 2010: 15 ), we must remain alert to law's paradoxical character: its capacity to provide valuable information about our past on the one hand and its tendency to minimize and distort important elements of our history of child sexual abuse on the other.

\section{Acknowledgements}

Special thanks to Emily Grabham, Rosemary Hunter and Thanos Zartaloudis who provided helpful written comments on drafts. The participants in seminars at the following Law Schools helped me develop my thoughts: University of Kent, University College Dublin, Dublin City University, University of Technology, Sydney and University of Melbourne. Many thanks to the anonymous reviewers for their insightful comments on the paper.

\section{Declaration of Conflicting Interests}

The author(s) declared no potential conflicts of interest with respect to the research, authorship, and/or publication of this article. 


\section{Funding}

The author(s) disclosed receipt of the following financial support for the research, authorship, and/or publication of this article: This research was supported by a Socio Legal Studies Association Small Grant.

\section{Notes}

1. Smart (2000) asks this question in relation to the discursive struggle over the meaning of childhood, the innocence of girls and the discovery of venereal diseases in children's homes in early twentieth-century England.

2. A trial in due course of law is guaranteed under Article 38.1 of the Constitution.

3. Sections 28(1) and 28(6) of the Residential Institutions Redress Act 2002.

4. General Scheme of a Retention of Records Bill 2015.

5. Section 41 of the Youth Justice and Criminal Evidence Act 1999.

6. Section 7 of the Criminal Law (Rape) (Amendment) Act 1990 (Ireland); $R v$ Makanjuola [1995] 3 All ER 730 (England and Wales).

7. Parts III and IV, No.12 of Criminal Evidence Act 1992; In England and Wales these were introduced by sections 23-30 of the Youth Justice and Criminal Evidence Act 1999.

8. This case employed the closely related concept of inhibition.

9. See FC v Judge Kirby and the DPP [2005] IEHC 445; BC v Judge Kirby and the DPP [2005] IEHC 446.

10. JC v DPP (6 July 2000, unreported, Supreme Court); PO’C v DPP [2000] 3 IR 8.

\section{References}

American Psychiatric Association (2013) Diagnostic and Statistical Manual of Mental Disorders. Washington: American Psychiatric Publishing.

Buckley S (2013) The Cruelty Man: Child welfare, the NSPCC and the State in Ireland 18891956. Manchester: Manchester University Press.

Burgess AW and Holmstrom L (1974) Rape trauma syndrome. The American Journal of Psychiatry 131: 981-986.

Carolan M (2006) DPP seeks legal decision on delayed complaints of sex abuse. The Irish Times Tuesday January 24.

Chunn DE (2002) Secrets and lies: The criminalization of incest and the (re)formation of the 'private' in British Columbia, 1890-1940. In: McLaren J, Menzies R and Chunn DE (eds) Regulating Lives. Historical Essays on the States, Society, the Individual, and the Law. Vancouver: UBC Press, pp. 120-144.

Conroy B (2005) Clarifying the law on delayed prosecutions for sexual offences. Bar Review 10(6): 214.

Conway V (2014) Policing Twentieth Century Ireland. A History of a Garda Siochána. London: Routledge.

Commission to Inquire into Child Abuse (2009) Final Report. Dublin: Stationery Office.

Commission of Investigation (2009) Report into the Catholic Archdiocese of Dublin. Dublin: Stationery Office.

Commission of Investigation (2010) Report into Cloyne Archdiocese. Dublin: Stationery Office. Department of Justice, Equality and Law Reform (2005) Report of the Ferns Inquiry. Dublin: Stationery Office. 
Ellison L (2005) Closing the credibility gap: The prosecutorial use of expert witness testimony in sexual assault cases. International Journal of Evidence and Proof 9(4): 239-268.

Ellison L and Munro V (2009a) Reacting to rape: exploring mock jurors' assessments of complainant credibility. British Journal of Criminology 49(2): 202-219.

Ellison L and Munro V (2009b) Turning mirrors into windows? Assessing the impact of (mock) juror education in rape trials. British Journal of Criminology 49(3): 363-383.

Ferriter D (2009a) Occasions of Sin. London: Profile Books.

Ferriter D (2009b) Report by Dr Diarmuid Ferriter, St Patrick's College, DCU. In Commission to Inquire into Child Abuse, Final Report. Dublin: Stationery Office.

Gilfus ME (1999) The price of the ticket: A survivor-centered appraisal of trauma theory. Violence Against Women 5: 1238-1257.

Gavey N and Schmidt J (2011) Trauma of rape" discourse: A double- edged template for everyday understandings of the impact of rape? Violence Against Women 17(4): 433-456.

Haaken J (1998) Pillar of Salt: Gender, Memory and the Perils of Looking Back. New Brunswick: Rutgers University Press.

Hanly C, Healy D, Scriver S, et al. (2009) Rape and Justice in Ireland: A National Study of Survivor, Prosecutor and Court Responses to Rape. Dublin: The Liffey Press.

Holohan C (2011) In Plain Sight: Responding to the Ferns, Ryan, Murphy and Cloyne Reports. Dublin: Amnesty International Ireland.

Irwin-Zarecka I (1994) Frames of Remembrance: The Dynamics of Collective Memory. New Brunswick: Transaction.

Keenan M (2012) Child Sexual Abuse and the Catholic Church: Gender, Power, and Organizational Culture. New York: Oxford University Press.

Kitzinger J (1997) Who are you kidding? Children, power and the struggle against sexual abuse. In: James A and Prout A (eds) Constructing and Reconstructing Childhood. Basingstoke: The Falmer Press, pp. 165-189.

Mahoney MR (1994) Victimization or oppression? Women's lives, violence and agency. In: Fineman MA and Mykitiuk R (eds) The Public Nature of Private Violence. New York: Routledge, pp 59-92.

Maguire M (2007) The Carrigan committee and child sexual abuse in twentieth-century Ireland. New Hibernia Review 11(2): 79-100.

O’Malley T (2009) The Criminal Process. Dublin: Round Hall.

Pine E (2010) The Politics of Irish Memory: Performing Remembrance in Contemporary Irish Culture. Basingstoke: Palgrave.

Powell F, Geoghegan M, Scanlon M, et al. (2013) The Irish charity myth, child abuse and human rights: Contextualising the Ryan report into care institutions. British Journal of Social Work 43: 7-23.

Raitt F and Zeedyk S (2000) The Implicit Relation of Psychology and Law: Women and Syndrome Evidence. London: Routledge.

Ring S (2009) Beyond the reach of justice? Complainant delay historic child sexual abuse cases and the right to a fair trial. Judicial Studies Institute Journal 2: 162-203.

Ring S (2013) Analysing 'fairness in context' in historic child sexual abuse prosecutions. Irish Criminal Law Journal 23(4): 132-140.

Sheehy E, Stubbs J and Tolmie J (1992) Defending battered women on trial: the battered women's syndrome and its limitations. Criminal Law Journal 16: 369. 
Smart C (2000) Reconsidering the recent history of child sexual abuse, 1910-1960. Journal of Social Policy 29(1): 55-71.

Stefan S (1994) The protection racket: rape trauma syndrome, psychiatric labelling, and law. Northwestern Law Review 88: 1271-1345.

Temkin J and Krahé B (2008) Sexual Assault and the Justice Gap: A Question of Attitude. Oxford: Hart.

Temkin J, Gray JM and Barrett J (2016) Different functions of rape myth use in court: Findings from a trial observation study. Feminist Criminology: 1-22 published online 4 August 2016. DOI: 10.1177/1557085116661627. Accessed 5 January 2017.

Walker L (1984) The Battered Woman Syndrome. New York: Springer.

Wells C (1994) Battered women syndrome and defences to homicide: Where to now? Legal Studies 14: 266-276.

Woodiwiss J (2014) Beyond a single story: The importance of separating 'harm' from 'wrongfulness' and 'sexual innocence' from 'childhood' in contemporary narratives of childhood sexual abuse. Sexualities 17(1/2): 139-158.

Young A (1998) The wasteland of the law. The wordless song of the rape victim. Melbourne University Law Review 22(2): 442-465.

\section{Cases cited}

$B v D P P$ [1997] 3 IR 140.

$B C$ v Judge Kirby and the DPP [2005] IEHC 446.

$D P P$ v JO'C unreported High Court, 27 July, 2001.

$F C v$ Judge Kirby and the DPP [2005] IEHC 445.

$J O ' C$ v DPP [2000] 3 IR 478.

$J C$ v DPP (6 July 2000, unreported), Supreme Court.

$J L v D P P$ [2000] 3 IR 122.

$P C \vee D P P$ [1999] 2 IR 25.

$P C \vee D P P$ [2005] IEHC 103.

$P C v$ Malone [2002] 2 IR 560.

People (DPP) v Synott (29 May 1992, unreported), Court of Criminal Appeal.

$P J C$ v DPP [2005] IEHC 98.

$P O^{\prime} C$ v DPP [2000] 3 IR 87.

$R v$ Makanjuola [1995] 3 All ER 730.

$R C v D P P$ [2005] IEHC 97.

$S A v D P P$ [2005] IEHC 262.

$S F v D P P[1999] 3$ IR 235.

$S H v D P P[2006] 3$ IR 575.

$T S v D P P[2005] 2$ IR 595.

\section{Legislation cited}

Criminal Law (Rape) (Amendment) Act 1990.

Residential Institutions Redress Act 2002.

Youth Justice and Criminal Evidence Act 1999. 